\title{
HALlaZgOS DE UN NAUFRAGIO EN EL PUERTO DE BUENOS AIRES
}

\author{
FINDS FROM A SHIPWREK IN BUENOS AIRES HARBOR
}

\author{
Mónica Patricia Valentini ${ }^{1}$ \\ Recibido 18 de junio 2021. Aceptado 27 de septiembre 2021
}

\begin{abstract}
Resumen
Durante la excavación de rescate del pecio de Zencity en Puerto Madero, ciudad de Buenos Aires, se extrajeron una gran cantidad de materiales. De ellos no todos formaban parte de la carga que venía en el buque o pertenecían al buque mismo. En el transcurso del estudio pudimos constatar que los procesos posdeposicionales y la situación de ser zona de fondeo el lugar del hallazgo hizo que pensáramos en diferentes contextos. El estudio de cada uno de los materiales nos posibilitó interpretar esos contextos y vislumbrar ciertas hipótesis de trabajo. El naufragio no se nos presentaba como una "capsula de tiempo" en su totalidad.

Palabras clave: pecio, procesos posdeposicionales, contextos arqueológicos
\end{abstract}

\begin{abstract}
During the rescue excavation of the Zencity wreck in Puerto Madero, city of Buenos Aires, a large quantity of materials were extracted. Not all of them were part of the cargo that came on the ship or belonged to the ship itself. During the course of the study, we were able to verify that the postdepositional processes and the situation of being the anchoring area the place of the discovery, made us think in different contexts. The study of each of the materials allowed us to interpret these contexts and glimpse certain working hypotheses. The wreck was not presented to us as a "time capsule" in its entirety.
\end{abstract}

Key words: wreck, postdepositional processes, archaeological contexts

\section{Introducción}

Buenos Aires, prácticamente en los confines del sistema colonial, se vio incorporada al mercado mundial por medio del comercio de ultramar, tanto por vías lícitas como ilícitas. Para mediados del siglo XVIII funcionaba lo que Jumar definió como un "complejo portuario rioplatense" (Jumar, 2011, p. 208), que articulaba distintos circuitos. Este complejo portuario, en su momento de mayor extensión entre 1730 y 1820, estuvo conformado principalmente por la ciudad de Buenos Aires, las ciudades puertos de Colonia do Sacramento y Montevideo. Aunque también cabe mencionar a los apostaderos secundarios de Maldonado, Ensenada de Barragán y atracaderos clandestinos con mayor o menor estructura y tránsito, siempre en aguas del Río de la Plata (Camarda, 2015; Jumar, 2011; Jumar et al., 2006). Buenos Aires participaba de este comercio exportando metales preciosos y, mayoritariamente, con la venta de cueros proveniente de las tierras del interior y del ganado cimarrón, que se había expandido considerablemente. De ultramar se importaban esclavos, por vía ilegal, desde Brasil y legalmente de África, que ingresaban por el puerto de Montevideo. Ambos circuitos, el legal y el ilegal, importaban además todo tipo de insumos que no existían en la ciudad, tales como azúcar, café, tabaco y productos manufacturados (Borucki, 2009). Por otra parte, el Río de la Plata ofrecía puertos de aprovisionamiento para el retorno, reparaciones a los barcos que muy frecuentemente llegaban con averías debido a la larga travesía por el Atlántico y todo tipo de servicios para los marinos mientras permanecían en la ciudad (Jumar et al., 2006).
Entre enero del 2009 y abril del 2010, a partir de una excavación de rescate o de urgencia, se recuperó una gran cantidad de materiales arqueológicos que formaban parte del contexto primario y secundario de un buque de madera naufragado en la costa del Río de la Plata y que fue denominado Pecio de Zencity (García Cano, en prensa). Por las características arquitectónicas pertenecería a un mercante español de mediano porte de fines del siglo XVIII que arribó al Puerto de Nuestra Señora de los Buenos Aires con la carga en su bodega. Una fuerte tormenta lo habría varado en las cercanías de la boca del Riachuelo y luego de rescatar algunos enseres la tripulación lo dejó a merced de las aguas del Río de la Plata. Entre los elementos recuperados, especialmente en lo que podemos denominar el contexto primario de los restos naufragados, nos encontramos con una gran cantidad de objetos que formaban parte de la carga de la embarcación. Otros, que pertenecerían a un contexto secundario, tienen que ver con el proceso de formación de sitio y los contextos posdepositacionales en un ambiente de alta dinámica fluvial. Luego los restos del naufragio fueron cubiertos por la sedimentación.

1 Centro de Estudios en Arqueología Subacuática Argentina. Facultad de Humanidades y Artes. Universidad Nacional de Rosario. Email: mopavalentini@gmail.com 


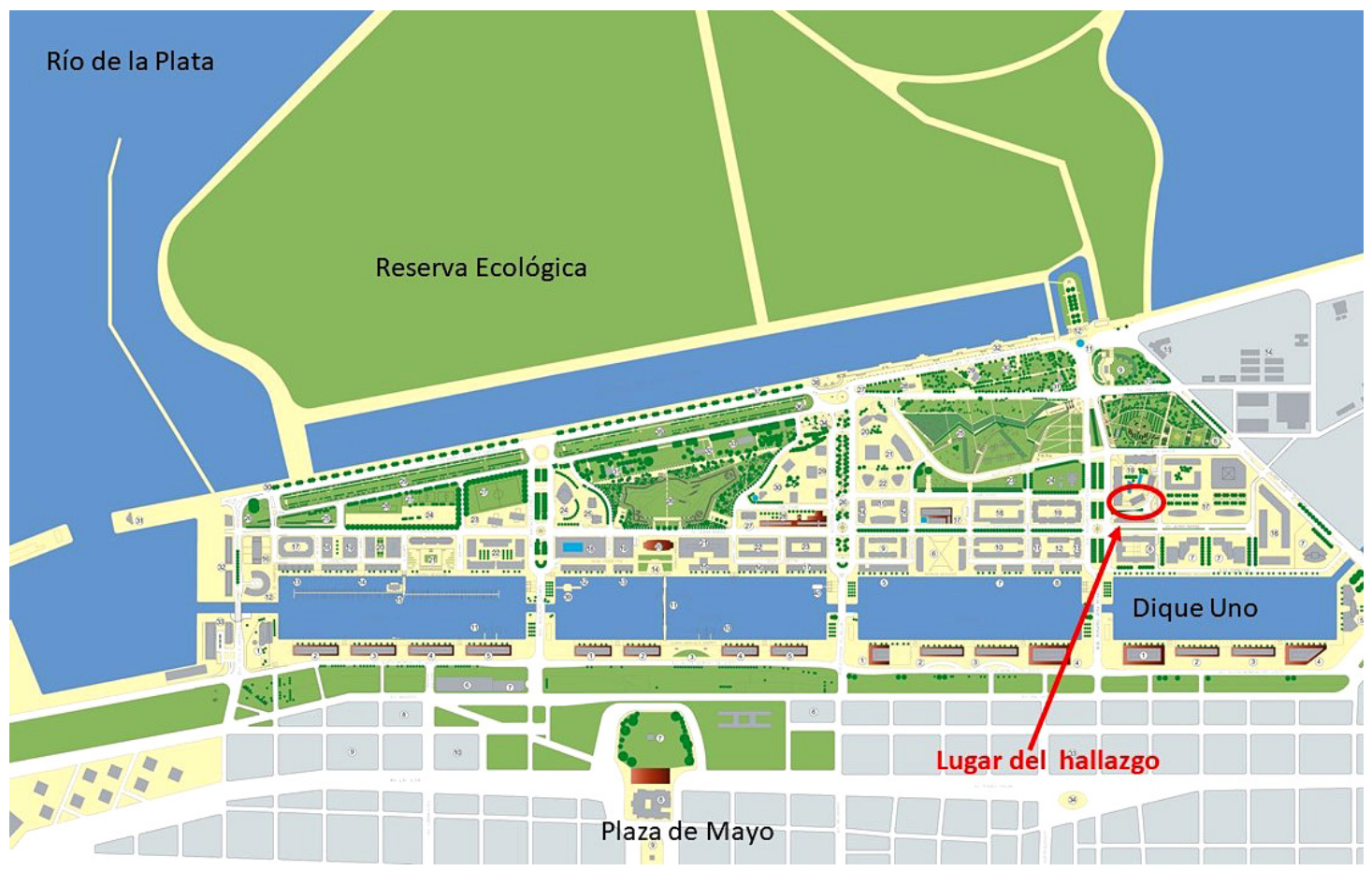

Figura 1. Localización del hallazgo en Puerto Madero, Buenos Aires. Plano Madero www.buenosaires.gob.ar

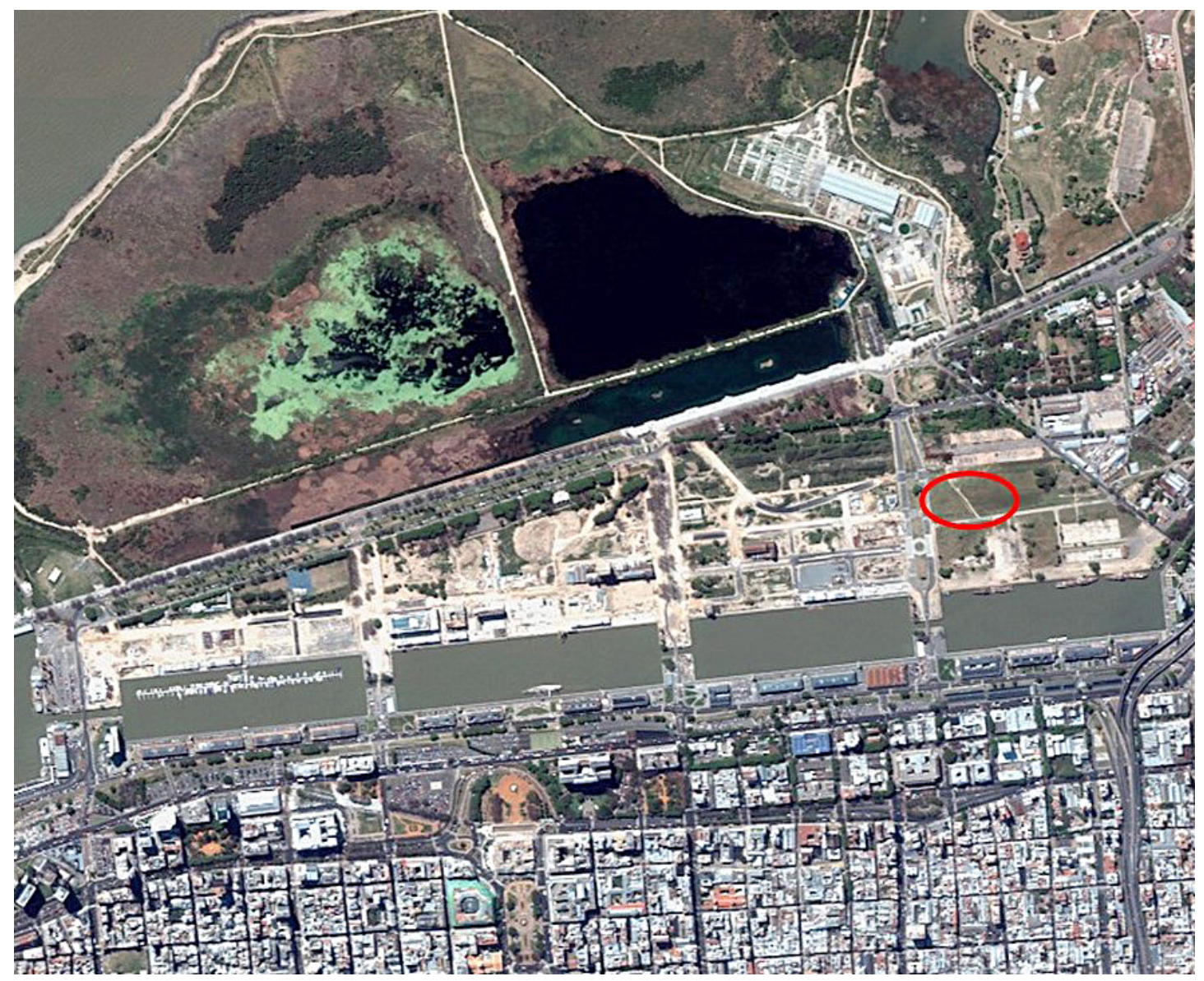

Figura 2. Fotografía satelital con ubicación del hallazgo www.buenosaires.gob.ar 


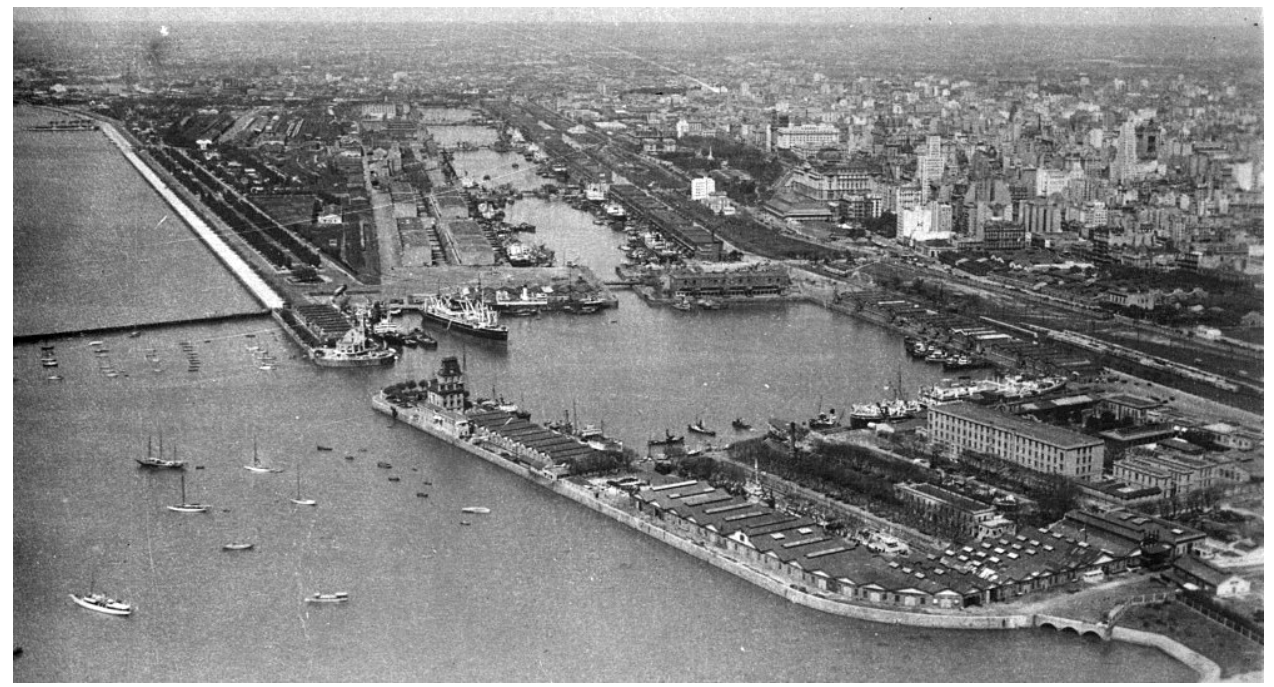

Figura 3. Vista de Puerto Madero desde Dársena Norte. https://www.histarmar.com.ar/Puertos/BsAs/DarsenaNorte

El Puerto de Buenos Aires fue, desde la conquista, un escenario o espacio de destino de diferentes tipos de mercancías, a bordo de naves que llegaron a estas tierras con materiales destinados a la ciudad y sus habitantes. En este capítulo presentaremos una selección de objetos recuperados, especialmente aquellos que formaron parte de la carga, porque refleja la diversidad de los bienes comerciales y la riqueza de los intercambios entre Buenos Aires y otras partes del mundo.

\section{EI sitio arqueológico: el hallazgo del naufragio}

En el sitio excavado la variabilidad de los objetos recuperados, además de la embarcación, estaba dada por botijos o contenedores cerámicos de una arroba $(15 \mathrm{~kg})$ y de media arroba, restos de toneles o barriles, algunos utensilios tales como azuelas, hachas, un cuchillo, una cuchara, cuatro cañones de hierro y una carga de platinas de hierro. Muchos de estos materiales fueron encontrados en su posición de estiba original en la bodega. Entre otros objetos recuperados se hallan aquellos que formaban parte de la estructura naval, como clavos de hierro de diferentes tamaños, pernos con y sin chaveta, tachuelas, aros $\mathrm{y}$ argollas, $110 \mathrm{~m}$ lineales de cabos de diferentes materias primas y 12 toneladas de piedras de lastre. También forman parte del registro 214 fragmentos de cerámica indígena, un número similar de pequeños fragmentos de lozas, 28 restos de pipas de cerámica y caolín (entre hornillos y boquillas), una considerable cantidad de restos óseos animales, 1246 de los cuales 770 son de bos taurus (Silveira \& Valentini, 2017) y un gran número de restos malacológicos (Valentini, 2012c). Debemos aclarar que parte de estos materiales enumerados se encontraron en un contexto secundario y que tal vez formaban parte del sitio producto de la dinámica fluvial y del proceso postdeposicional a la que el pecio fue expuesto hasta su total enterramiento por la sedimentación natural primero y la artificial con la construcción de Puerto Madero después (de Haro, 2018; Marcomini \& López, 2011; Valentini, 2012a).

El emplazamiento donde fue hallado el Pecio de Zencity, si bien hoy día está ubicado en tierra firme, en otros tiempos formó parte del cauce del Río de La Plata. En el caso del pecio, al quedar varado en las proximidades de la orilla, por la dinámica fluvial propia del Río de la Plata y del gran proceso de sedimentación del Riachuelo, que se ubica en las proximidades, se convirtió en un elemento de atracción de todo objeto que estaba siendo arrastrado por las aguas. También se habrían depositado los desechos arrojados desde la costa. Incluso, con las bajantes, el área se pudo haber transformado en un lugar de circulación pedestre con actividades de los lugareños quienes habrían dejado, dentro o en proximidad del pecio, diversos objetos enteros o fragmentados (de Haro, 2018).

Por eso es que podemos hallar dentro de él y/o en sus proximidades objetos que no conforman el contexto primario del evento, sino que forman parte de un contexto secundario, fruto de la acumulación de elementos que fueron captados por la atracción ejercida por los restos del barco. Por ser el Río de la Plata un vector fluvial con mucho arrastre de sedimentos es probable que el barco quedara varado o atascado en los bancos y/o barras de arenas formados a partir de esa dinámica fluvial. Luego de haber tenido una avería (se observó durante la excavación arqueológica la rotura de una sección de la quilla) el navío quedó imposibilitado para seguir navegando (Valentini, 2012b). Eran conocidas, entre los marinos, las grandes dificultades de la navegación en el Río de la Plata y especialmente el fondear en las cercanías de Buenos Aires (Guagliardo, 2012; Lezama, 1999).

\section{Materiales recuperados en contexto primario}

\section{Contenedores cerámicos: botijos}

Entre los elementos que formaban parte de la carga del barco se encontraron contenedores cerámicos denominados "Botijas" entre los autores españoles y "olive jar" entre los de habla inglesa (Goggin, 1960; Marken, 1994). Por su cantidad, entre fragmentadas y enteras, las piezas de una arroba del Zencity conforman una de las mayores colecciones en la Argentina, hallándose solo seis contenedores de $1 / 2$ arroba entre ellos (De Grandis, 2012; Valentini, 2011). 

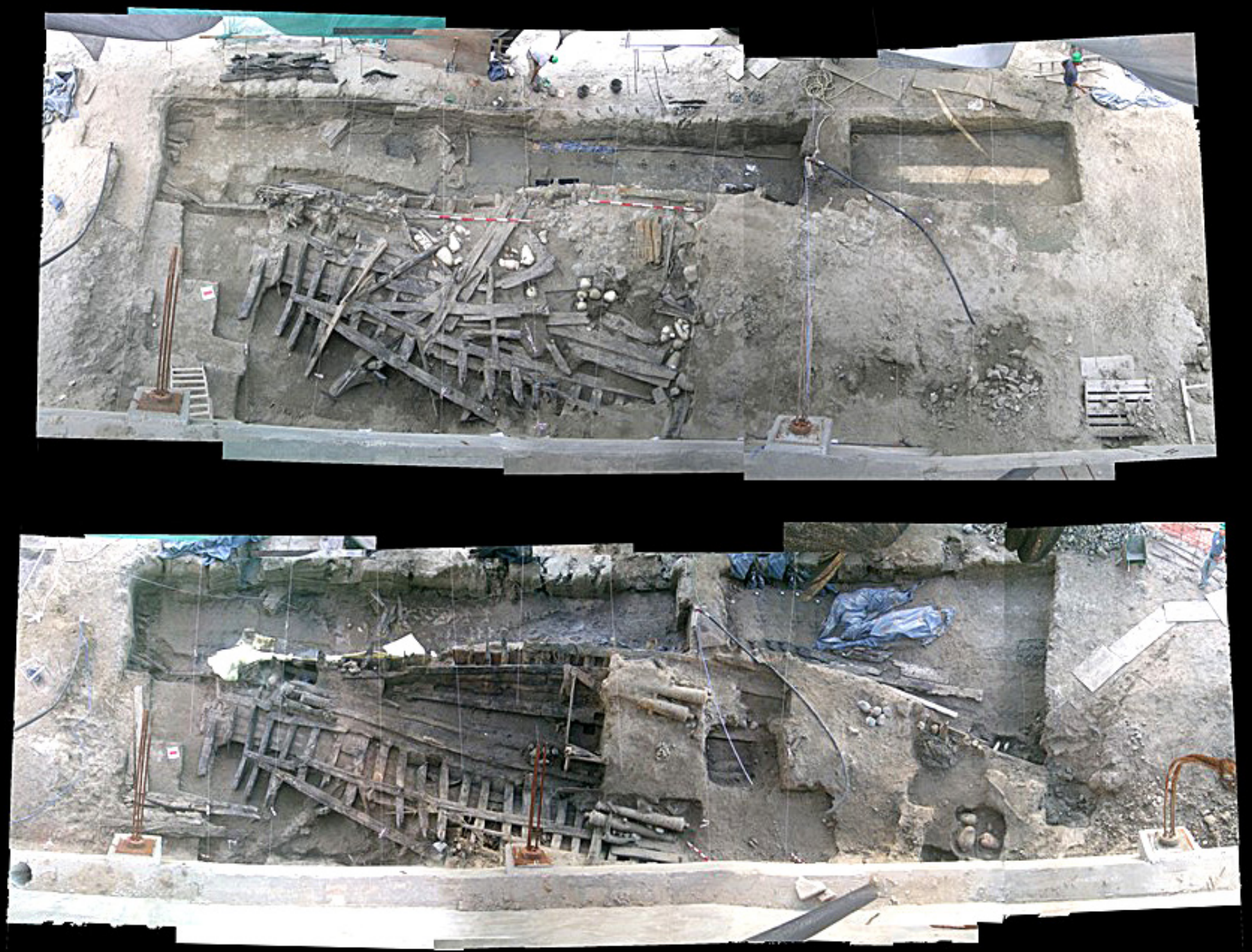

Figura 4. Procesos de excavación (Fotografía Javier García Cano)

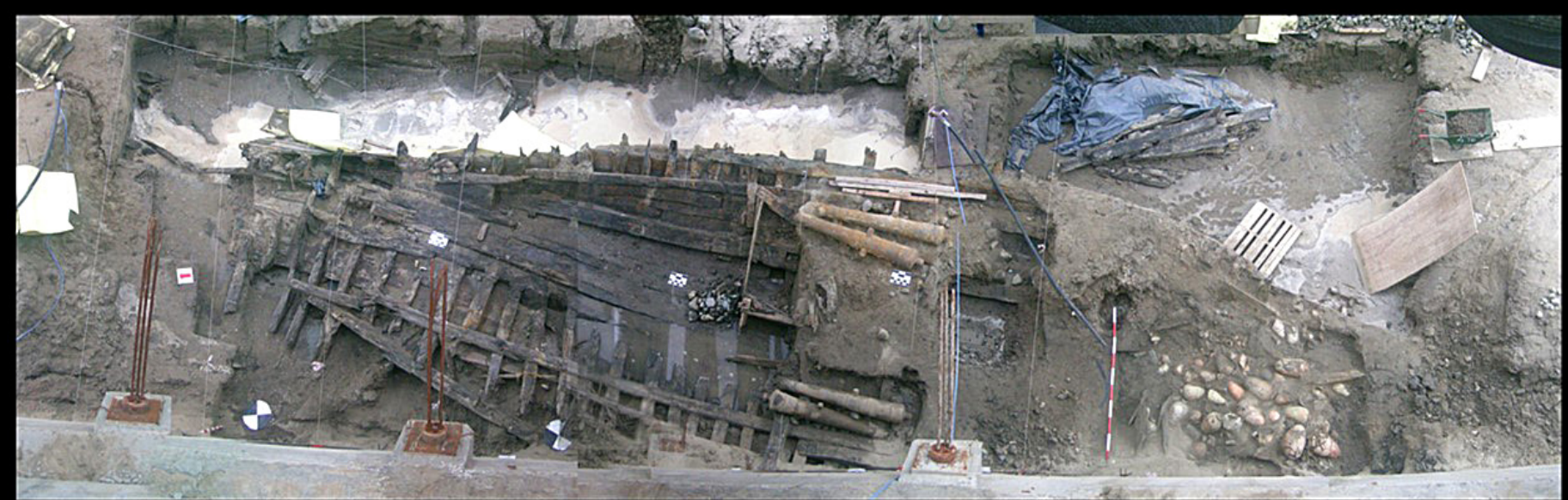

Figura 5. Procesos de excavación (Fotografía Javier García Cano). 
Para el transporte en las embarcaciones españolas que iban a los puertos americanos, hubo una gran cantidad de envasescontenedores que se utilizaron para el comercio de mercaderías, las cuales tuvieron una amplia distribución en la América Colonial (Deagan, 1987, p. 23). Estos tipos, provenientes en gran medida de los alfares andaluces, se estibaban en las bodegas de las embarcaciones con distintos productos para comerciar y con aquellos necesarios para la travesía y la supervivencia de la tripulación. Entre la bibliografía que trata este tipo de objetos el texto de John Goggin (1960) puede ser considerado como uno de los más importantes, habiendo realizado la primera tipología sobre "jarras de aceite", luego completada y ampliada por Marken (1994) y James (1988). Entre otros Deagan (1987) describe a estos contenedores como cerámica utilitaria.

De acuerdo con estos estudios, la tipología de las botijas halladas en el pecio de Zencity pueden ubicarse en el período medio definido por Goggin (1960), coincidiendo con la cronología en la que se circunscriben los restos del pecio para el siglo XVIII (Mundo, 2013). Utilizados para el transporte de una gran variedad de productos, presentaban características morfológicas que hacían fácil su estiba y organización en la bodega de los barcos que cruzaban el Atlántico. Durante la excavación arqueológica se pudo observar este hecho ya que, a pesar del proceso de varadura y rotura de la quilla de la embarcación, del paso del tiempo y del proceso de transformación del sitio, se encontraron un gran número de estas piezas en su lugar de estiba corroborándose que las mismas permanecieron sin averiarse durante la travesía.

La limpieza de estos envases en el laboratorio y el análisis de muestras sobre las sustancias y sedimentos en su interior, nos han brindado información sobre su contenido. Se pudo constatar la presencia de brea, resina de pino y olivas (Si bien por medio de observación directa constatamos la presencia de estos tres materiales en el interior de algunas botijas, se enviaron muestras al Laboratorio de Materiales del Instituto Valenciano de Conservación y Restauración de Bienes Culturales de la Generalitat de Valencia, España, en el mes de marzo del 2009. Es importante mencionar que el contenedor de una arroba que tenía en su interior los carozos de olivas fue hallado con tapón de corcho). Estos tres elementos sin duda formaban parte de la carga ya que se hallaron en el interior de los botijos. Los dos primeros posiblemente utilizados para el calafateo y reparación de los bajeles, tanto durante la travesía como también para comerciar en los puertos. Las olivas, provenientes entre otras de la península, eran muy comunes en el comercio con las colonias (Mena García, 2004; Sánchez Sánchez, 1996; Zunzunegui, 1965).

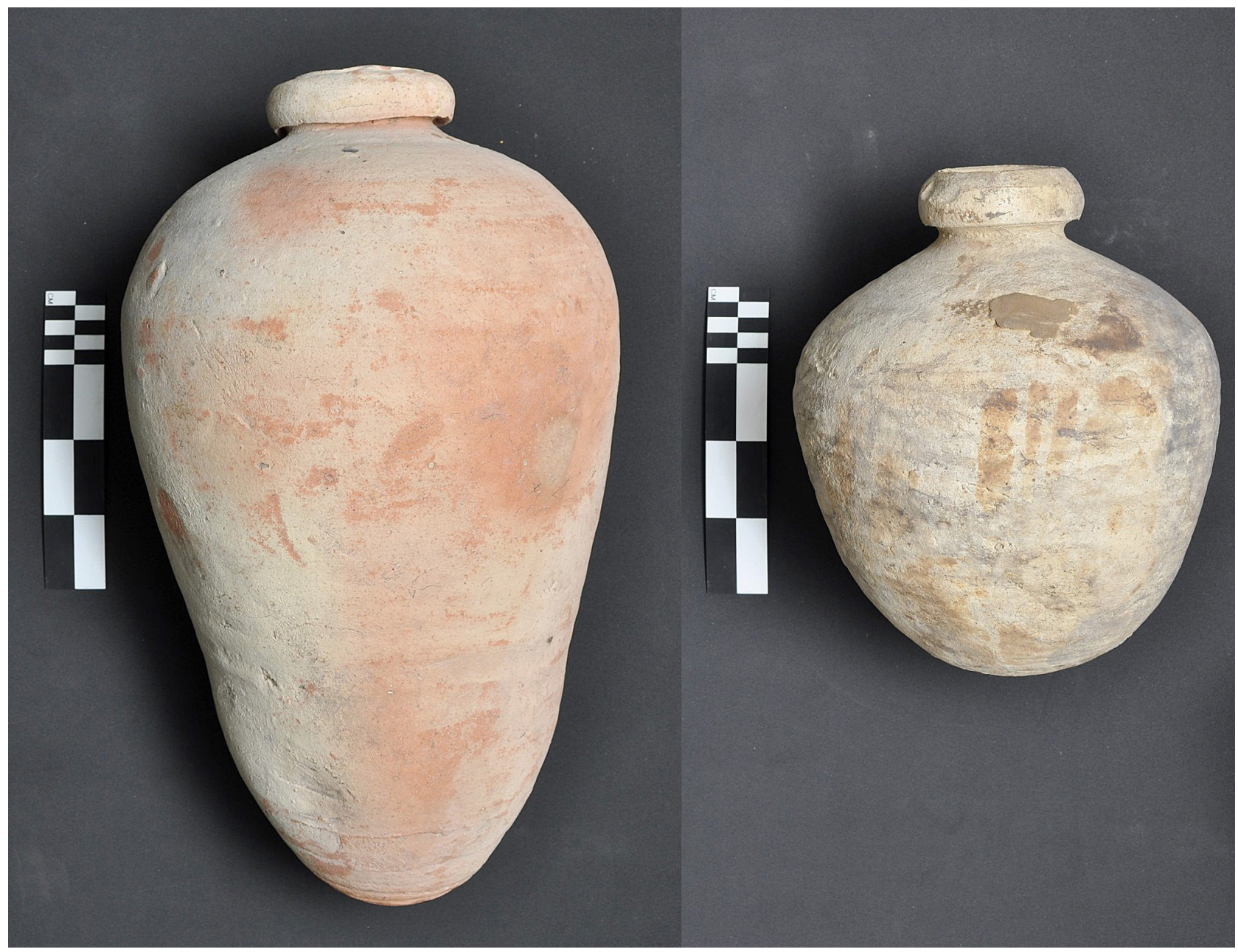

Figura 6. Botijos españoles de una y media arroba en la carga del barco (Fotografías Javier García Cano). 


\section{Cañones}

Cuatro cañones de hierro perfectamente estibados en lo que habría sido la bodega del barco causaron siempre un interés especial, no solo a quienes los investigábamos sino también al público en general. Estas piezas se presentan iguales, mismo peso, medidas y material constructivo, son lo que podríamos definir como fabricaciones en serie, muy comunes para las armas de este período (Valentini, 2016). Los estudios metalográficos realizados nos muestran que la morfología de las piezas está compuesta con un porcentaje de inclusión de titanio que se corresponde a las minas suecas (Medina et al., 2012).

A estos cañones se les hizo una limpieza mecánica que, además de quitarles el óxido, nos permitió observar dos inscripciones. Una de ellas en uno de los muñones y otra en el anillo de base. La marca " $F$ " en el muñón determina que la fundición de las piezas fue realizada en Suecia en la fábrica de Finspong, denominados, con el correr del tiempo y tal vez la deformación del vocablo por los idiomas, "Finbankers" (Frantzen, 2001; Stelten, 2010). La inscripción en el anillo de base establece el peso, en este caso son 1210 libras (1210 A). La letra "A" se la relaciona con libras de Amsterdam. Creemos que, aunque el cañón se fundió en Suecia, por la "F" de Finspong en el muñón, fue posiblemente comercializado a través de Holanda, lo que no es extraño ya que las primeras fundiciones en Suecia fueron concesiones de la corona a mercaderes holandeses, que aportaron el knowhow (conocimiento) mientras el rey de Suecia les cedió minas, bosques para carbonear y esclavos procedentes de la guerra de los 30 años (Ryden \& Floren, 1997).

\section{Talla en madera, ¿ex voto?}

Un vestigio único entre los objetos recuperados del pecio de Zencity ha merecido un especial interés, es una pequeña madera tallada encontrada en la sección de la carlinga del palo mayor. Esta presenta una serie de dibujos de embarcaciones cuyo significado o intención desconocemos. Han hecho pensar en la posibilidad de alguna ofrenda votiva con motivos rituales por parte de los tripulantes para arribar a tierra al final de su viaje. Esta es una posible interpretación dado que salir a la mar era siempre una aventura peligrosa y las tradiciones marineras de todas las épocas así lo demuestran. Las supersticiones, las creencias, los

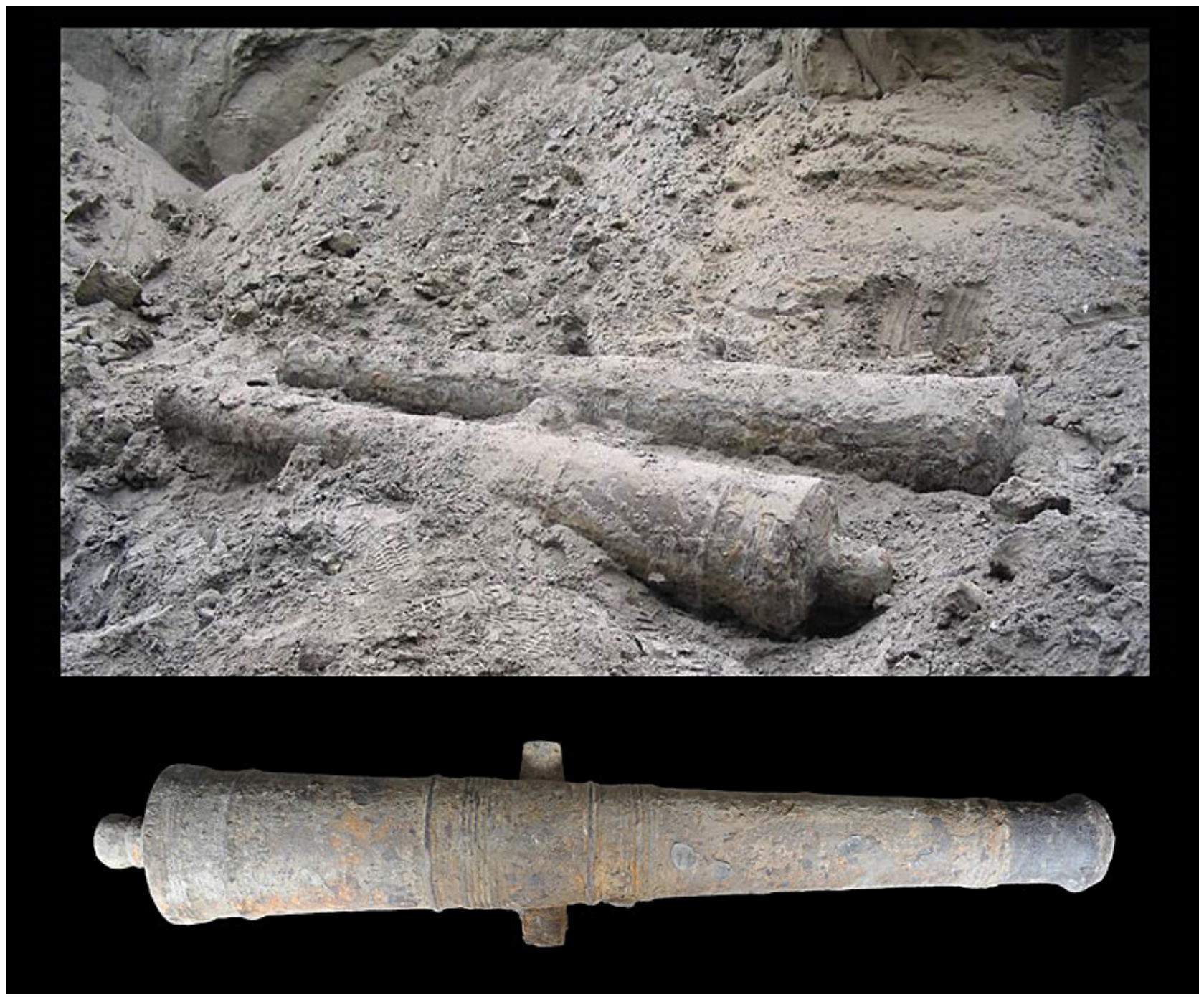

Figura 7. Cañones suecos cargados en bodega y cañón limpio (Fotografías Javier García Cano). 

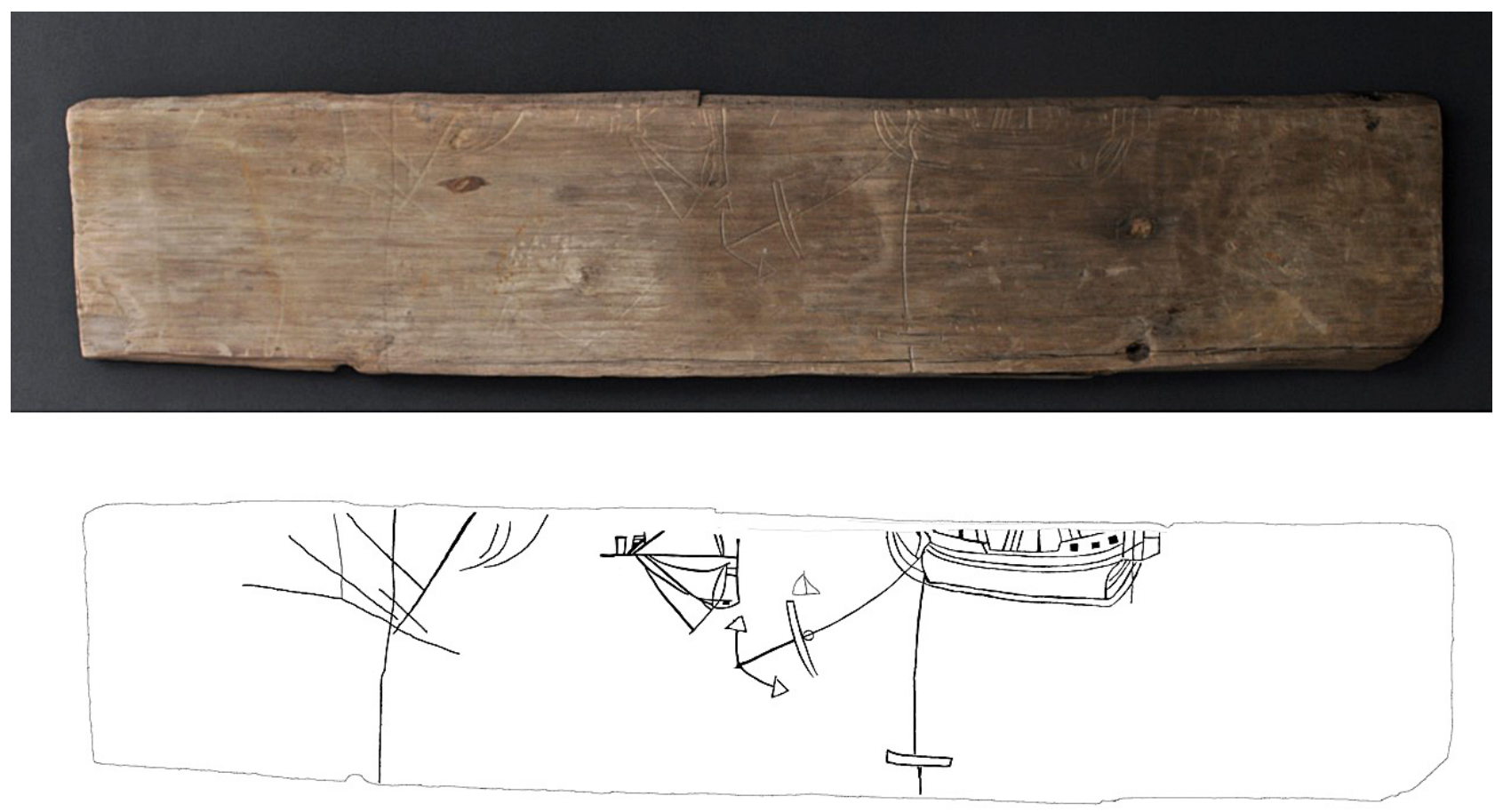

Figura 8. Madera con grabados. Fotografía Javier García Cano (Dibujo Romina Carvalho).

mitos y toda suerte de prácticas religiosas eran comunes entre los tripulantes y especialmente en las zonas costeras de donde zarpaban los barcos a la travesía (Armendariz, 2009). Otra hipótesis podría dar cuenta de un simple tallado de una expresión artística durante el largo viajes entre España y América.

\section{Monedas}

Otras piezas que podrían enmarcarse en las tradiciones marinas son dos resellos de cobre españoles. También denominados calderillas o cuartillos fueron ubicados cercanos a la quilla y entre el palo mayor y el trinquete. Eran de uso común en la península, pero no circularon en la región del Río de la Plata (Fontela Ballesta, 2007). Si bien en 1680 se prohíbe la circulación de este tipo de monedas en España, su retiro nunca tuvo éxito pleno o inmediato. Por lo que no se puede descartar cierta perdurabilidad especialmente en los sectores rurales españoles (Fontela Ballesta, 2007). La costumbre de colocar monedas en la base de los mástiles durante la construcción de los buques, data de largo tiempo atrás y es una antigua superstición que se relaciona con la ofrenda o pago a Caronte, el viejo barquero que transporta almas, según la mitología griega (Rodríguez López, 2008). Costumbre que muchos astilleros y armadores aún llevan adelante. El análisis de los resellos nos ubica entre los años 1641 y1665 (Centeno Yañez, 2006). Los estudios dendrocronológicos realizados nos dan una datación de corte y posible construcción para la segunda mitad del siglo XVIII (Mundo, 2013; Valentini, 2018). Por lo que nos acercamos a pensar que estas monedas tenían más que ver con alguna de las supersticiones arraigadas en la cultura marinera (Valentini, 2020). Los mismos astilleros tanto militares como privados del imperio español tenían y tienen en la actualidad la costumbre de colocar la moneda de la suerte en las embarcaciones construidas.

\section{Alcarrazas}

Entre el conjunto de cultura material que conformaba el registro arqueológico primario del sitio, hallamos una gran cantidad de fragmentos cerámicos finos, blanquecinos y frágiles que llamaron nuestra atención ya que no teníamos referencia de hallazgo en otros contextos arqueológicos de espacio y tiempo similares en nuestro país. Para tener más información acerca del tipo de contenedor al que correspondían los fragmentos se decidió que los restauradores/conservadores remontaran y reconstruyeran las piezas (Valentini, 2012). Una vez realizado el remontaje, en primer lugar, se determinó que se trataba de un tipo de contenedores definidos por Deagan (1987) como "cerámica bizcocho".

En cuanto a su forma y función, siguiendo la sugerencia de especialistas de la Universidad de Sevilla (Pleguezuelo \& Amores Carredano - comunicación personal 27 de marzo y 21 de abril de 2012- ) fue de gran utilidad recurrir a fuentes iconográficas consistentes en imágenes de obras pictóricas del barroco español. De esta manera, la Historia del Arte como fuente de información nos brindó apoyo a la investigación, ya que pudimos observar ejemplos de cuándo y cómo ciertos objetos fueron producidos, así como también su funcionalidad (Orser, 2000). Las formas y usos se nos revelaron al ver ciertas pinturas de artistas españoles del siglo XVII como Zurbarán, Murillo, Velázquez, Meléndez, Pereda y otros. A partir de estas imágenes, es posible concluir que las piezas en cuestión corresponden a las denominadas por Pleguezuelo (2000) y por Amores Carredano (2009), como "cerámica para agua" o "cerámicas finas", respectivamente. La cerámica "bizcocho" de la que habla Deagan es justamente una cerámica porosa, poco cocida, que permite mantener frescos los líquidos en su interior por sudoración, rezumados o evaporación (Amores Carredano, 2009; Pleguezuelo, 2000). Ambos autores 


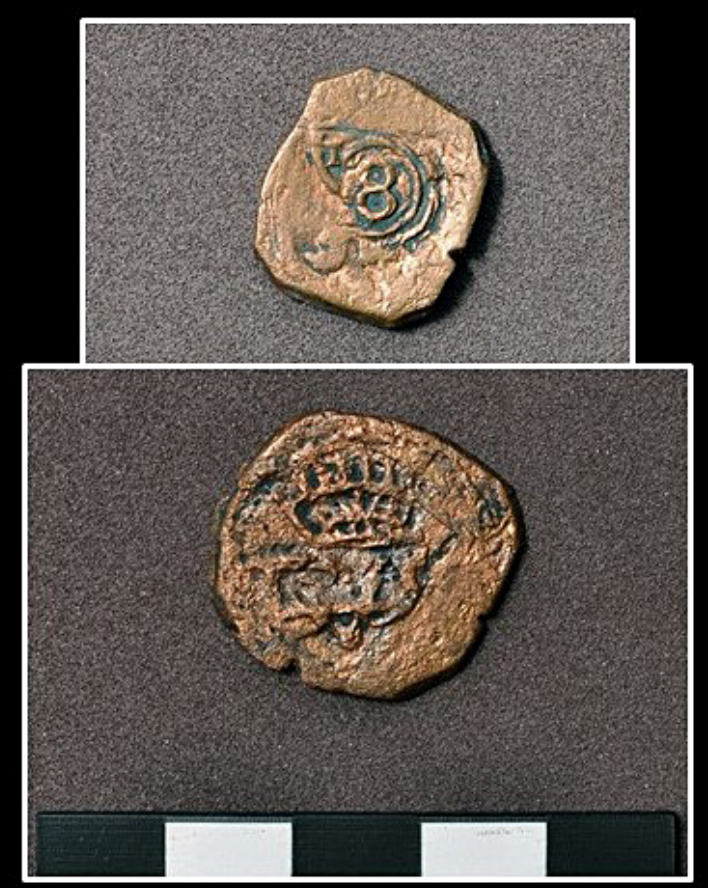

Figura 9. Resellos españoles

(Fotografía Mónica Valentini).
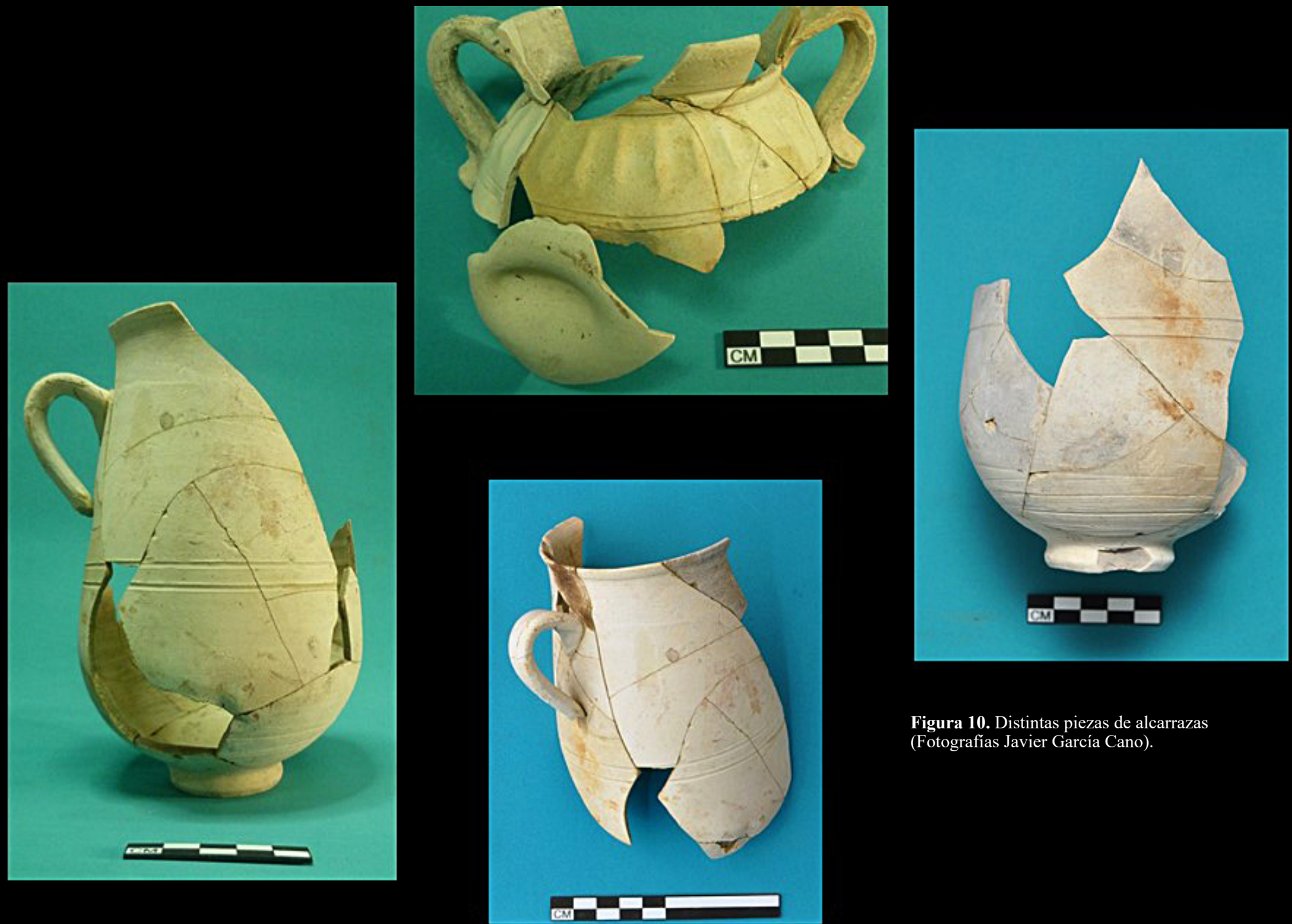

Figura 10. Distintas piezas de alcarrazas (Fotografías Javier García Cano) 
las denominan "alcarrazas": "(...) es un nombre que denomina ante todo un tipo de alfarería fabricada con pasta muy blanquecina de composición calcárea, torneada de paredes extremadamente finas y usadas, igual que los búcaros, para refrescar el agua de beber" (Pleguezuelo, 2000, p. 135). Debemos considerar el origen musulmán del vocablo, lo que no es de extrañar ya que los alfares de este tipo de cerámicas se encontraron principalmente en el territorio andaluz (Amores Carredano, 2009; Lister \& Lister, 1987).

Estas "alcarrazas trianeras", en referencia al barrio de Triana en Sevilla, eran conocidas como de "cascarón de huevo" por la finura del barro con que se hacían (Pleguezuelo, 2000). Cabe resaltar que, tanto los autores españoles como los americanos que consultamos hacen referencia a la fragilidad de estas piezas y de que no se han hallado nunca enteras en las excavaciones arqueológicas (Amores Carredano, 2012; Pleguezuelo, 2011). La gran cantidad de fragmentos encontrados y las variadas formas que pudimos reconstruir, nos hacen pensar como hipótesis en que estas piezas podrían haber formado parte de la carga que venía en el buque (Valentini, 2012a).

\section{Elementos de arquitectura naval}

Los restos del buque tienen 21,47 $\mathrm{m}$ de largo, 5,33 $\mathrm{m}$ de ancho y un máximo de 2,06 $\mathrm{m}$ de altura en la zona del codaste en la popa. Toda la estructura corresponde a lo que se denomina la zona de obra viva del buque, no habiéndose identificado material que formara parte por encima de la línea de flotación o incluso cubierta y borda. La sección más alta del casco fue ubicada desarticulada de los restos principales del casco. Este fragmento corresponde al espejo de popa, y fue localizado algunos metros al norte del casco. Cuenta con 4,16 m de ancho (medidos en paralelo a la manga del buque) y una altura de $2,65 \mathrm{~m}$.

La geometría y dimensiones de los restos del casco proponen un tipo de nave de tamaño promedio mediano para su época de las utilizadas para transporte de mercaderías. Era una embarcación apta para la navegación oceánica, con una sola bodega y una cubierta. Tanto la circunstancia de Buenos Aires hasta el inicio del siglo XIX como las características de la arquitectura del buque coinciden con las necesidades de una ciudad que se sostuvo gracias a una economía de servicios y comercio, y que fue factible a partir de la presencia de estas naves de carga y transporte (Jumar et al., 2006, p. 12).

La madera utilizada para la construcción del buque es el roble de la región cantábrica (Quercus robur). "En relación con la estructura de la embarcación las muestras analizadas de diferentes secciones nos llevan a la conclusión de que se utilizó la madera de roble para su construcción" (Castro, 2012, p. 88).

Con respecto a los materiales de hierro utilizados en la construcción del barco, se analizaron elementos de fijación o ensamblado: tachuela, clavo y perno de ligazón. La tachuela posee la forma constructiva adecuada para la sujeción de revestimientos y está confeccionada con un acero de alto contenido de carbono que, por su dureza asegura una buena capacidad de penetración en el clavado. De acuerdo con lo observado se considera que el contenido de carbono logrado se obtuvo por cementación de un alambre o fleje que fue posteriormente forjado. El clavo es de hierro forjado de escaso contenido de carbono con una forma de fabricación típicamente manual como era la práctica normal y exclusiva hasta fines del siglo XVIII. La superficie de la pieza posee rastros de un leve aumento del contenido de carbono que revela un aporte exterior de algún medio cementante. El perno es del tipo que se fijaba con una arandela y chaveta para asegurar una fijación robusta. Fue fabricado por forja con un acero de bajo contenido de carbono y se le practicó un aporte de carbono desde la superficie para obtener una capa cementada de $2,5 \mathrm{~mm}$. Todos los elementos analizados son de hierro forjado, producidos manualmente según la tecnología de fabricación habitual del siglo XVIII, consistentemente con las técnicas españolas reportadas. Se destaca el manejo de conceptos metalúrgicos asociados a técnicas de cementación vinculadas a la funcionalidad de los elementos tendiente a obtener propiedades mecánicas acordes a la utilización de estas (De Rosa et al., 2009; Medina et al., 2012).

\section{Otros materiales recuperados: el contexto secundario}

Entre otros materiales, ya sin conformar la carga del barco o del contexto del episodio del naufragio, hallamos una gran cantidad de huesos de animales. Estos 1246 restos óseos no provendrían de comidas de los tripulantes del pecio. Podemos afirmar que los restos óseos presentaron una dispersión o distribución pareja en todo el sitio y que se encontraron en los niveles de sedimentación natural que comenzaron a cubrir el buque (Silveira \& Valentini, 2017). La totalidad o casi totalidad de estos huesos estaban en el ámbito del Río de la Plata y se introdujeron en el casco de la embarcación luego que fuera abandonada, como consecuencia de la acción dinámica del río. Estimamos esto sucedió entre fines del siglo XVIII y principios del XIX. Salvo huesos de peces y de algunas aves acuáticas, el resto de ellos provienen de ámbitos terrestres del interior cercano, siendo un alto porcentaje de Bos taurus. Estos huesos pudieron ser basura de los habitantes de la ciudad, de los mataderos o hasta incluso resultado de la gran mortandad de ganado que sucedió durante la Gran Sequía entre 1827 y 1832 (Silveira \& Valentini, 2017).

Entre los restos óseos cabe mencionar tres artefactos de hueso reconocidos, cuya asociación con el pecio no puede determinarse. Consisten en 2 punzones pequeños y un desata nudos ( $f i d$ en inglés). Este último pudo pertenecer a algún tripulante de la embarcación u otra que llegara al puerto de Buenos Aires.

También se hallaron 28 piezas que corresponden a restos de pipas, algunas de caolín y otras de cerámica, producidas a mano o de molde, de delicados trazos y toscas, tubos y cazoletas, lo cual abre un sinfín de posibilidades en cuanto a quienes las utilizaron, a su procedencia y a cómo llegaron hasta allí. Pero sin duda un objeto muy común en la zona de puertos llena de tripulantes y embarcaciones (de Haro y Sportelli, 2017).

Junto a ellos nos encontramos también con un variado grupo de fragmentos cerámicos heterogéneos de adscripción hispano indígena o criolla, indígena y afroamericana, al que se denominó cerámica local y un conjunto similar de losas europeas. En la cerámica local se pueden observar los rastros de arrastre, rodamiento y desgaste producto de los procesos antes descriptos que los afectaron (de Haro, 2018)

\section{Comentarios finales}

La investigación de este sitio fue estructurada en el marco de lo que podemos denominar "Arqueología de Rescate o de Urgencia». En este caso constituyó una respuesta científica a la alteración y destrucción de los bienes culturales no renovables, 


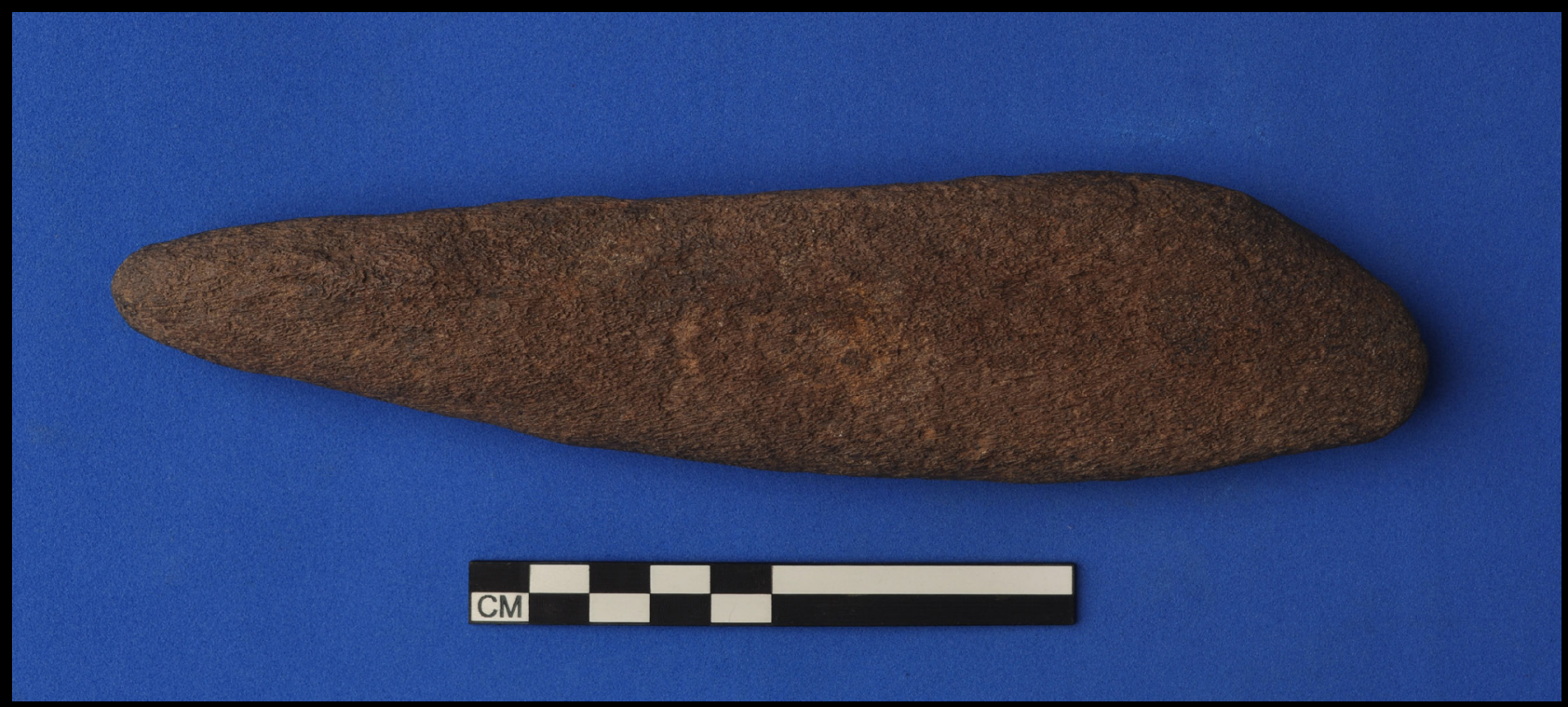

Figura 11. Instrumento “fid" (Fotografía Mónica Valentini).
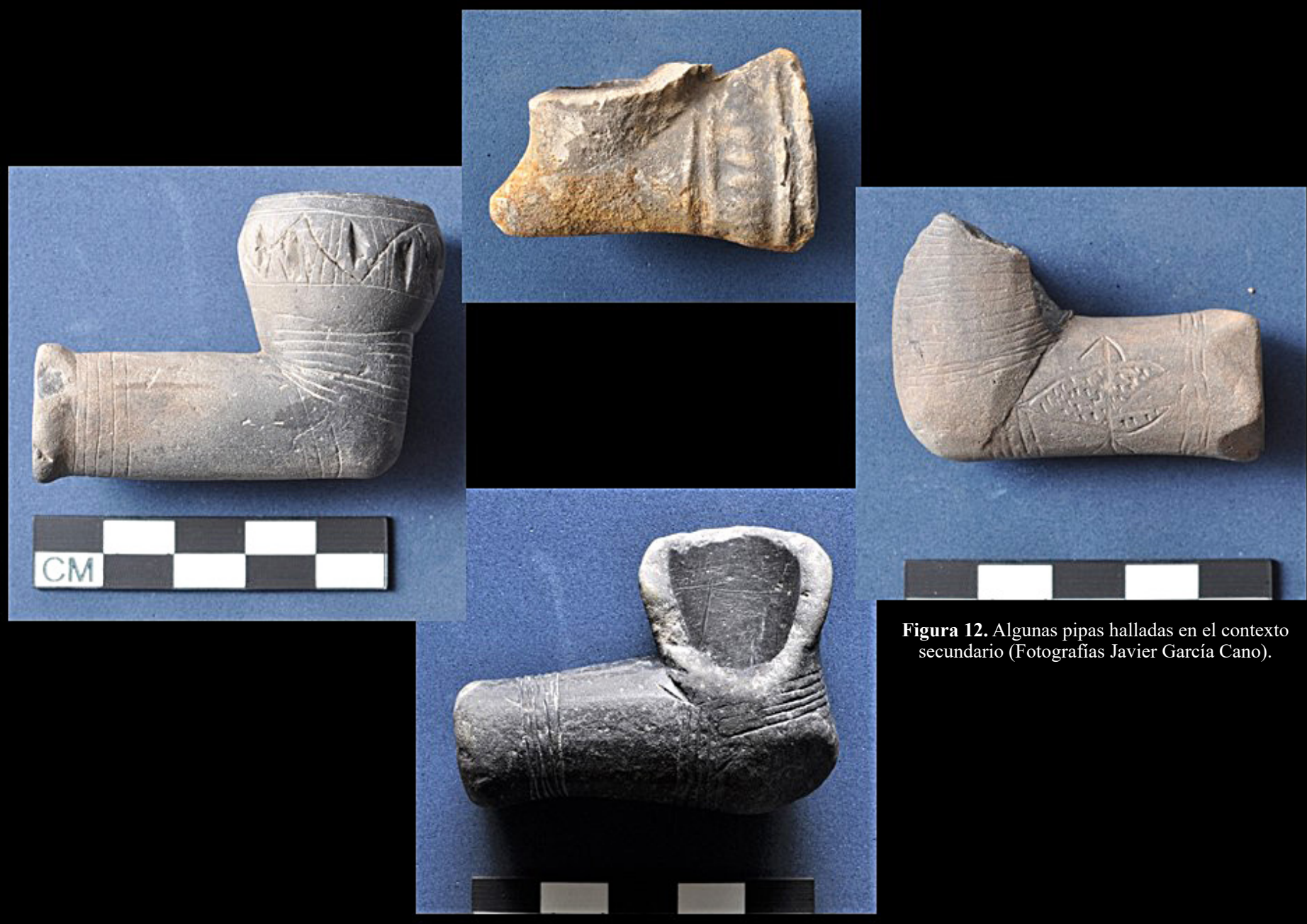

Figura 12. Algunas pipas halladas en el contexto secundario (Fotografías Javier García Cano). 


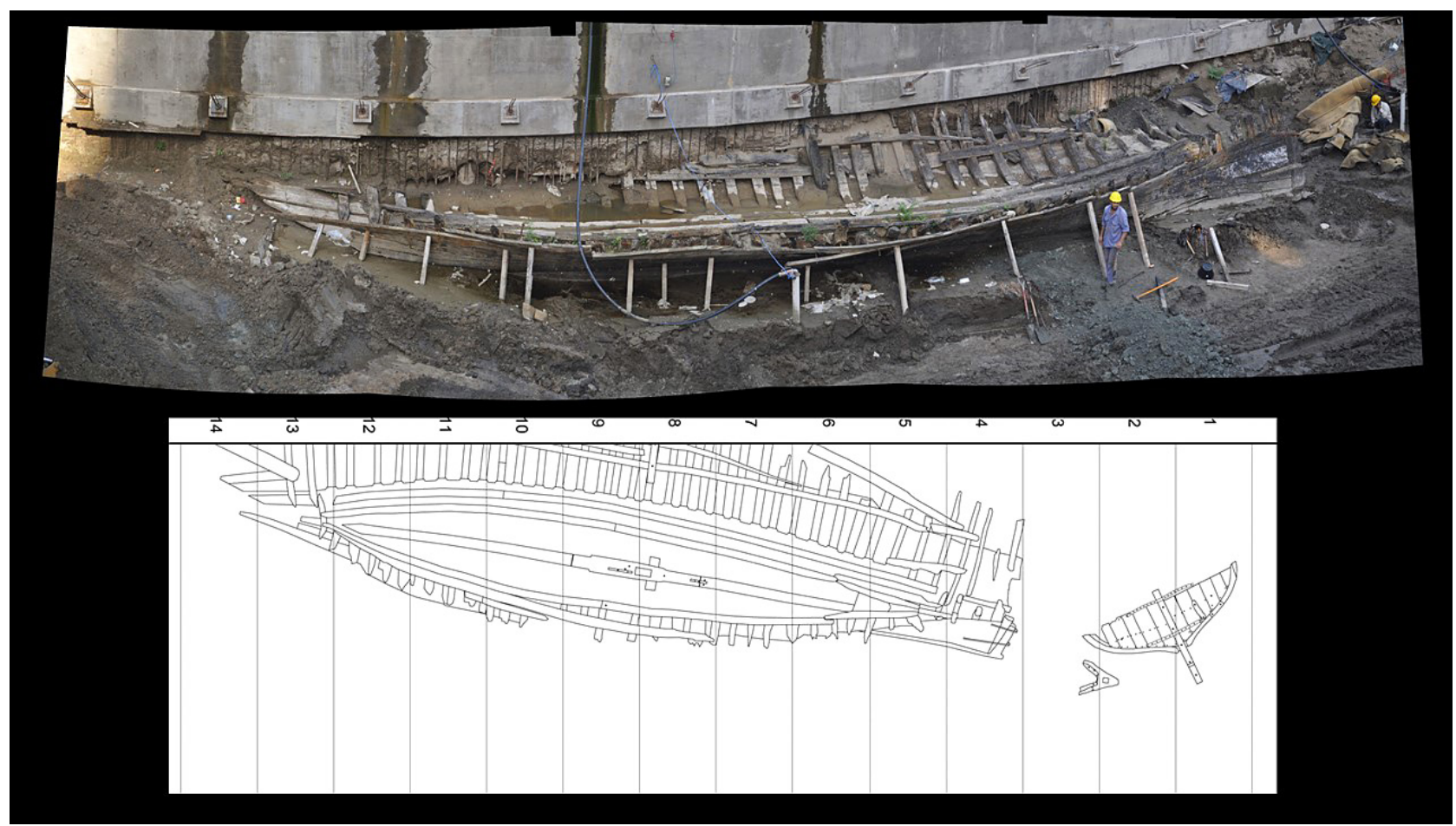

Figura 13. Restos del pecio totalmente al descubierto y plano de los restos en AutoCAD (Fotografía Mónica Valentini; dibujo de Rosario Johnson).

orientando los esfuerzos metodológicos a la inminente pérdida del sitio arqueológico por el avance de una obra en construcción.

Más allá del contexto del naufragio, la cultura material refleja la dinámica sedimentaria del puerto de Buenos Aires, pero también los cambios en el paisaje costero a través del tiempo. La evidencia recuperada se interpreta en relación con una cultura material más amplia que tiene que ver con dos niveles de análisis al que sometimos el registro arqueológico en este caso. Aquellos que podían evidenciarse como parte de la carga y denominamos contexto primario. $\mathrm{Y}$ el resto que sin duda estaban relacionados con el proceso de formación y conformaron un contexto secundario y que no podíamos circunscribir al momento del naufragio: la actividad portuaria, los desechos urbanos y la sedimentación, tanto natural como artificial.

En todo el mundo las ciudades puerto jugaron un papel preponderante en el flujo de personas y mercancías (Jumar, 2012). El registro arqueológico nos permite evidenciarlo, así como observar que el tipo de registro que se encuentra en los pecios es muy variado y hasta ecléctico, especialmente en un sitio como el aquí considerado, donde los procesos de formación fueron tan dinámicos

Reconstruir las redes comerciales, entre la metrópoli y su periferia, en un período histórico, donde el contrabando y los navíos de registro eran una práctica común y hasta tolerada, donde gran parte de la carga no aparece en la documentación de las autoridades portuarias de la época, hace que el registro material a través de la arqueología nos permita completar la historia y conocer prácticas y hasta supersticiones de diferentes grupos humanos (Valentini, 2020).

Sin duda el pecio de Zencity y sus materiales asociados, evidencian la interacción de la ciudad de Buenos Aires y su puerto en el contexto colonial y comercial de la época.

\section{Bibliografía}

Amores Carredano, F. \& López Torres, P. (2009). Las cerámicas finas - alcarrazas blancas - de Sevilla en la Edad Moderna: la expresión barroca de una expresión almohade. En R. Cruz-Auñón Briones \& E. Ferrer Albelda (Eds.), Estudios de Prehistoria y Arqueología en Homenaje a Pilar Acosta Martínez (pp. 563-573). Sevilla: Universidad de Sevilla.

Armendariz, X. (2009). Exvotos y ofrendas marineras en el País Vasco: estado del estudio e inventariado de materiales votivos marítimos. Revista de Estudios Marítimos del País Vasco, 6, 381- 402.

Borucki, A. (2009). Las rutas brasileñas del tráfico de esclavos hacia el Río de la Plata. En Actas $4^{\circ}$ Encontro escravidao e Liverdade no Brasil Meridional, 1777-1812. Curitiba.

Camarda, M. (2015). La región Río de la Plata y el comercio ultramarino durante las últimas décadas del siglo XVIII: actores, circulación comercial y mercancías. (Tesis para optar por el grado de Doctor en Historia). Facultad de Humanidades y Ciencias de la Educación, Universidad Nacional de La Plata, La Plata.

Castro, M. (2012). Análisis de estructuras vegetales. En M. Valentini \& J. García Cano (Eds.), Un Mercante español en el Puerto de Buenos Aires. Historia y Hallazgos en Puerto Madero (pp. 87-92). CABA: Dirección General de Patrimonio e Instituto Histórico.

Centeno Yáñez, J. (2006). Las Monedas Reselladas de Felipe III y Felipe IV (1603-1659). Estudio y catalogación. Córdoba, España: El Autor. 
De Grandis, N. (2012). Barcos mercantes y tráfico comercial en la costa del Río de la Plata. Las botijas de media arroba. Revista del Centro de Estudios de Arqueología Histórica, 1, 109-118.

de Haro, M.T. (2018). Pecio de Zencity: la otra cerámica. Procesos de formación o ¿cómo llegó esto aquí? Revista de Arqueología Histórica Argentina y Latinoamericana, 12(60), 1428-1451.

de Haro, M.T. \& Sportelli, P. (2017). Las pipas y su variabilidad en un naufragio. Anti. Revista del Centro de Investigaciones Precolombina, 15, 211-223.

De Rosa, H.; Svoboda, H. \& Machuca Suarez, A. (2009). Caracterización de elementos de fijación de un navío hallado en la ciudad de Buenos Aires (proyecto Zencity). Ponencia presentada en el Congreso SAM/CONAMET, Buenos Aires.

Deagan, K. (1987). Artifacts of the Spanish Colonies of Florida and the Caribbean, 1500-1800.Vol. 1. Washington, D.C.: Smithsonian Institution.

Frantzen, O.L. (2001). Finbankers. Journal of the Ordnance Society, 13, 5-24.

Fontenla Ballesta, S. (2007). Un depósito numismático de finales del Siglo XVII. Alberca, 5, 53-56.

Goggin, J. (1960). The Spanish Olive Jar: an introductory study. Yale University Publications in Anthropology, no. 62. New Haven: Yale University Press.

Guagliardo, J.P. (2012). El infierno de los marinos. Arqueología de naufragios en el Río de la Plata. Madrid: Editorial Académica Española.

James, S. (1988). A reassessment of the chronological framework of Spanish Olive Jar. Historical Archaeology, 22(1), 42-66.

Jumar, F.; Biangardi, N.; Bozzo, J.; Orlowski, S.; Querzoli, R. \& M.E. Sandrín. (2006). El comercio ultramarino y la economía local en el Complejo Portuario Rioplatense siglo XVIII. Anuario IEHS, 21, 35-49.

Jumar, F. (2011). Comerciantes en Río de la Plata pre-virreinal. El caso de Domingo de Basavilbaso. Anuario del Instituto de Historia Argentina, 11, 207-241.

Jumar, F. (2012). La región Río de la Plata y su complejo portuario durante el Antiguo Régimen, En R. Fradkin (Ed.), Historia de la provincia de Buenos Aires. De la conquista a la crisis de 1820, Tomo 2 (pp. 123-157). Buenos Aires: Edhasa.

Lezama, A. (1999). Historia debajo del mar (la parte). Introducción a la arqueología subacuática en el Río de la lata. Anales de Prehistoria y Arqueología, 15, 141:165.

Lister, F.C. \& Lister, R. (1987). Andalusian Ceramics in Spain and New Spain. A Cultural Register from the Third Century B.C. to 1700. Tucson: The University of Arizona Press.

Marcomini, S. \& López, R.A. (2011). Historia de la costa de Buenos Aires. Ciencia Hoy, 21, 41-48.

Marken, M. (1994). Pottery from Spanish shipwrecks, 15001800. Gainesville: University Press of Florida.

Medina, M.; López, A.; Svoboda, H. \& De Rosa, H. (2012).
Caracterización microestructural de piezas de fundición de un navío mercante español del siglo XVIII. Ponencia presentada en $12^{\circ}$ Congreso Binacional de metalurgia y Materiales CONAMET/SAM 2012, Valparaíso.

Mena García, C. (2004). Nuevos datos sobre bastimentos y envases en armadas y flotas de la Carrera. Revista de Indias, 64(231), 447-484.

Mundo, I. (2013). Dendrochronological dating of the Puerto Madero Vessel, Buenos Aires, Argentina. Ponencia presentada en el Second American Dendrochronology Conference, Tucson.

Orser, C. (2000). Introducción a la Arqueología Histórica. Buenos Aires: Tridente.

Pleguezuelo, A. (2000). Cerámicas para agua en el barroco español: una primera aproximación desde la literatura y la pintura. Ars Longa, 9-10, 123- 138.

Rodríguez López, M.I. (2008). Arqueología y creencias del mar en la antigua Grecia. Zephyrus, LXI, 177-195.

Ryden, G., \& Floren, A. (1997). Convergencia tecnológica y diversidad social. Mercados, centros de producción y cambio tecnológico en la industria del hierro europea, 1600-1850. Revista de Historia Industrial, 12, 75-111.

Sánchez Sánchez, J.M. (1996). La cerámica exportada a América en el siglo XVI a través de la documentación del Archivo General de Indias. I. Materiales arquitectónicos y contenedores de mercancías. Laboratorio de Arte. Revista del Departamento de Historia del Arte, 9, 125-142.

Silveira, M. \& Valentini, M. (2017). Un fechado intrigante. Teoría y Práctica de la Arqueología Histórica Latinoamericana, 6(6), 143-150.

Stelten, R. (2010). Relics of a Forgotten Colony. The Cannon and Anchors of St. Eustatius. Leiden: Leiden University.

Valentini, M. (2011). El comercio ultramarino y la producción industrial para el sostenimiento colonial. Un caso en el puerto de Buenos Aires. Ponencia presentada en Conferencia Internacional TICCIH 2011, Requena, España.

Valentini, M. (2012a). Refrescando el agua. Las alcarrazas en el pecio de Zencity, Revista de la Escuela de Antropología, 18, 79-89.

Valentini, M. (2012b). Un barco, un puerto, una ciudad. En M. Valentini y J. García Cano (Eds.), Un mercante español en el puerto de Buenos Aires. Historias y Hallazgos en Puerto Madero (pp. 11- 16). Buenos Aires: Patrimonio e Instituto Histórico.

Valentini, M. (2012c). El registro arqueológico. Arqueología de un barco. En M. Valentini y J. García Cano (Eds.), Un mercante español en el puerto de Buenos Aires. Historias y Hallazgos en Puerto Madero (pp. 33-38). Buenos Aires: Patrimonio e Instituto Histórico.

Valentini, M. (2016). La industria del hierro sueco llegó al Río de la Plata. El caso de los "Finbankers" del pecio de Zencity. Revista Teoría y práctica de la Arqueología Histórica Latinoamericana, 4(4), 163-172. 
Valentini, M. (2018). Zencity, los restos de una embarcación. En Memoria del 56 Congreso Americanista de Salamanca, pp.1041-1049. Universidad de Salamanca, Salamanca.

Valentini, M. (2020). Los cuartillos del rey. Resellos en el pecio de Zencity, Buenos Aires, Argentina. Fazendo antropologia no Alto Solimões, 29, 119-130.

Zunzunegui, A.P. (1965). Recipientes cerámicos utilizados en el comercio de Indias. Boletín americanista, 19-27, 21-38. 
